\title{
Recurrent Coronary Artery Vasospasm in a Patient with Hepatocellular Carcinoma Treated with Sorafenib: a Case Report and Literature Review
}

\author{
Dae Hyun Lim', Jai Hoon Yoon', Dae Won Jun', Oh Young Lee', Byung Chul Yoon¹, Hang Rak Lee', Kyung Soo Kim², \\ Ho Soon Choi $^{1}$ \\ Divisions of ${ }^{1}$ Gastroenterology, ${ }^{2}$ Cardiology, Department of Internal Medicine, Hanyang University College of Medicine, Seoul, Korea
}

Received Dec. 10, 2019

Revised Jan. 24, 2020

Accepted Feb. 5, 2020
Tyrosine kinase inhibitors are widely used as targeted treatments for various malignancies. Sorafenib is an orally active tyrosine kinase inhibitor that blocks the signaling pathways of several growth factors. Its use is approved for various malignancies such as unresectable hepatocellular carcinoma, renal cell carcinoma, and gastrointestinal stromal tumors. Several adverse effects have been reported in the literature; however, cardiotoxicity is rare. We present a case of recurrent coronary vasospasm caused by short-term administration ( 5 days) of sorafenib. Since it caused refractory ischemia after re-administration, we had no choice but to stop the treatment. (J Liver Cancer 2020;20:67-71)

Keywords: Sorafenib; Coronary artery vasospasm; Variant angina; Tyrosine kinase inhibitor; Vascular endothelial growth factor inhibitor

\section{INTRODUCTION}

Sorafenib is an orally active tyrosine kinase inhibitor (TKI) that blocks tumor cell proliferation and angiogenesis by inhibiting vascular endothelial growth factor (VEGF) and other growth factors, such as Raf and platelet-derived growth factor. Many TKIs, including sorafenib, sunitinib, pazopanib, vandetanib, cabozantinib, axitinib, ponatinib, and regorafenib, are available for treating a variety of malignancies. Sorafenib has been approved for the treatment of advanced hepatocellular carcinoma (HCC). ${ }^{1,2}$ The known toxic effects of sorafenib include cutaneous skin reaction, diarrhea, and hypertension; however, cardiotoxicity is rare. ${ }^{3,4}$ There are

\section{Corresponding author : Ho Soon Choi}

Department of Internal Medicine, Hanyang University College of Medicine, 222 Wangsimni-ro, Seongdong-gu, Seoul 04763, Korea

Tel. +82-2-2290-8379, Fax. +82-2-2298-9183

E-mail; hschoi96@hanyang.ac.kr

https://orcid.org/0000-0003-3746-8742 several reports of myocardial ischemia caused by sorafenib. However, most ischemic cardiotoxicity involves obstructive coronary artery disease and the mechanism by which it causes myocardial ischemia is poorly understood. ${ }^{2}$ We report a case of recurrent coronary vasospasm provoked by sorafenib. The Institutional Review Board (IRB) granted a waiver of approval as this case report was limited to one case, there was no harm to the study subjects, and the study did not collect or record the subject's sensitive information (IRB number: 2020-01-043).

\section{CASE REPORT}

\section{Clinical findings}

A 59-year-old man presented to our emergency room with intermittent anginal chest discomfort lasting for 3 days. In the first attack, pain had developed at rest and resolved spon- 
taneously. He experienced a second attack on the next day and visited another hospital, at which time his symptoms resolved with sublingual nitroglycerin. However, the intensity of the pain increased and he visited our hospital 2 days later, where he had been diagnosed with chronic hepatitis B infection 11 years earlier and has been followed up periodically. He developed HCC 8 years prior and had undergone five sessions of transarterial chemoembolization (TACE). Recently, multiple vertebral metastases were confirmed. Since his residual liver function and performance status were acceptable, he was administered sorafenib 5 days before he re- ported to our emergency room. The initial laboratory findings showed normal levels of cardiac biomarkers (serum troponin-I, troponin-T) and B-type natriuretic peptide. An electrocardiogram (ECG) revealed newly developed T-wave inversion on V1 to V3 leads when compared to previous records (Fig. 1).

\section{Imaging findings}

Elective coronary angiography failed to reveal any stenotic lesions in the coronary artery. After ergonovine injection,
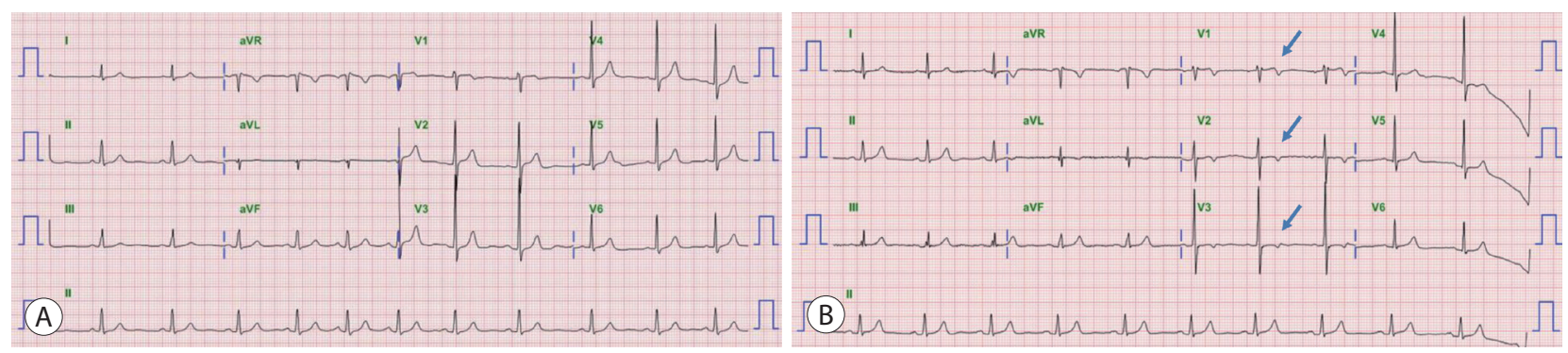

Figure 1. (A) Baseline electrocardiogram (ECG) obtained 2 months before symptom onset showing a normal sinus rhythm. (B) ECG at the time of presentation showing inverted T-wave in leads V1-V3 (arrows). aVR, augmented vector right; aVL, augmented vector left; aVF, augmented vector foot.
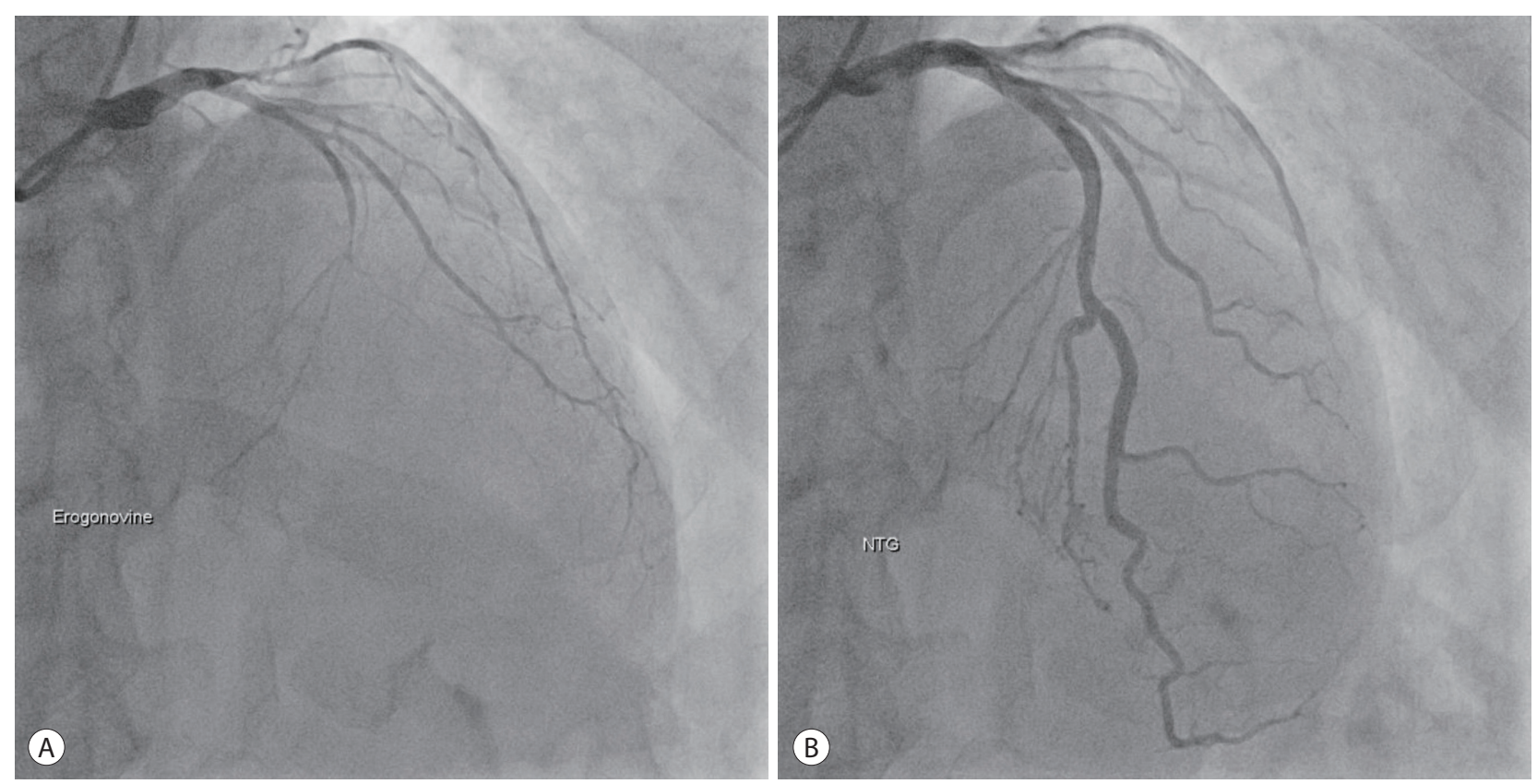

Figure 2. (A) After the provocation test (ergonovine injection), the middle of the left anterior descending artery, as well as the proximal left circumflex artery, have narrowed. (B) Following intracoronary nitroglycerin injection, the obstructed arteries have fully recovered. NTG, nitroglycerin. 
coronary angiography revealed total occlusion of the middle of the left anterior descending artery with elevated ST segment on ECG (Fig. 2). Additionally, the patient felt the same chest discomfort with diaphoresis. Intracoronary nitroglycerin was injected and the occluded artery was fully recovered.

\section{Diagnosis and treatment}

We diagnosed the patient with variant angina caused by coronary vasospasm. The patient had never drunk alcohol or smoked. He had no other underlying diseases, and did not take any medications except entecavir for hepatitis B. There was no obvious cause for the coronary vasospasm and so we suspected the interaction of sorafenib with the VEGF receptor as the main cause. Sorafenib was discontinued and the patient received the maximal tolerable doses of calcium channel blocker (nifedipine $60 \mathrm{mg}$ ) and antianginal agent

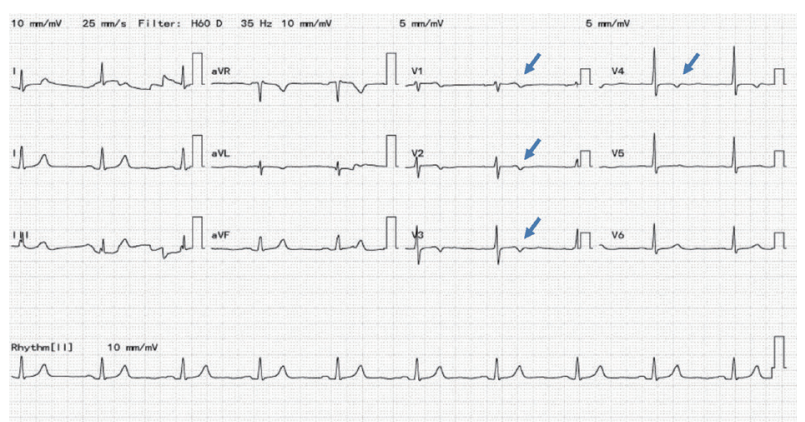

Figure 3. Electrocardiogram (ECG) obtained when the symptom recurred. The ECG shows T-wave changes in the anteroseptal leads (V1-V4). aVR, augmented vector right; aVL, augmented vector left; aVF, augmented vector foot. (nitrate). After that, the chest pain associated with his angina symptoms improved. We attempted to re-challenge with sorafenib and monitored his ECG with vital signs via a telecardiographic monitoring device. However, after re-administration of sorafenib, he experienced several bouts of chest pain with evidence of ischemic changes on an ECG despite taking maximal doses of nifedipine (Fig. 3). There was no choice but to discontinue sorafenib. Since discontinuation, his symptoms have not recurred. Regorafenib, a second-line treatment after sorafenib, was not administered because of concern that it might cause the same symptoms. Instead, additional TACE for HCC and radiotherapy for spinal metastasis were performed.

\section{DISCUSSION}

Many TKIs have been introduced and are widely used to treat various malignancies. They are currently approved for advanced or metastatic cancers such as HCC, renal cell carcinoma, and gastrointestinal stromal tumor. ${ }^{1,3}$ Sorafenib is a multi-TKI with activity against Raf, VEGF, and platelet-derived growth factor receptor tyrosine kinase. Several toxicities have been reported. While cardiotoxicity is rare, hypertension, myocardial ischemia, and heart failure can occur., Coronary vasospasm is a very rare adverse effect but total occlusion of the coronary artery induced by spasm, as in the present patient, may be life-threatening. ${ }^{7}$ So far, only three cases of coronary vasospasm during sorafenib treatment in patients with HCC or renal cell carcinoma have been report-

Table 1. Comparison of the four reported cases

\begin{tabular}{|c|c|c|c|c|c|c|c|}
\hline $\begin{array}{l}\text { Patient } \\
\text { (country, year) }\end{array}$ & Age/sex & Disease & $\begin{array}{l}\text { Therapy } \\
\text { duration }\end{array}$ & Event type & Coronary angiography & Re-challenge & Outcome \\
\hline $\begin{array}{l}\text { This case (South } \\
\text { Korea, 2018) }\end{array}$ & $59 / \mathrm{M}$ & $\mathrm{mHCC}$ & 5 days & Variant angina & $\begin{array}{l}\text { Normal with positive } \\
\text { provocation test }\end{array}$ & Yes & $\begin{array}{l}\text { Discontinued due to } \\
\text { recurrent symptoms }\end{array}$ \\
\hline $\begin{array}{l}\text { Arima et al. }{ }^{8} \\
\text { (Japan, 2009) }\end{array}$ & $65 / M$ & $\mathrm{mRCC}$ & 2 weeks & $\begin{array}{c}\text { Non-ST } \\
\text { elevation MI }\end{array}$ & $\begin{array}{l}\text { Normal with positive } \\
\text { provocation test }\end{array}$ & Yes & $\begin{array}{l}\text { Survived with } \\
\text { continuing drug }\end{array}$ \\
\hline $\begin{array}{l}\text { Naib et al. }{ }^{9} \\
(\text { US, 2011) }\end{array}$ & $57 / \mathrm{M}$ & $\mathrm{mHCC}$ & 11 months & ST elevation Ml & $\begin{array}{l}\text { Multivessel spasm with } \\
\text { baseline stenosis up to } 60 \%\end{array}$ & No & $\begin{array}{l}\text { Died with multiorgan } \\
\text { failure }\end{array}$ \\
\hline $\begin{array}{l}\text { Porto et al. } \\
\text { (Italy, 2010) }\end{array}$ & $63 / \mathrm{M}$ & $\mathrm{HCC}$ & $\begin{array}{l}\text { More than } \\
6 \text { months }\end{array}$ & Variant angina & $\begin{array}{l}\text { Normal with spontaneous } \\
\text { spasm }\end{array}$ & Yes & $\begin{array}{l}\text { Resumed without } \\
\text { symptoms }\end{array}$ \\
\hline
\end{tabular}

M, male; mHCC, metastatic hepatocellular carcinoma; mRCC, metastatic renal cell carcinoma; Ml, myocardial infarction. 
ed. ${ }^{8-10}$ All three cases developed ischemic heart disease by vasospasm without significant stenosis of the coronary artery. Detailed information about the four cases, including ours, is shown in Table 1. Unlike the patients in the previous cases, the present patient developed symptoms after only three days of sorafenib and the causal relationship between sorafenib administration and the development of coronary vasospasm was clear. First, there were no other risk factors for vasospasm. Second, the temporal connection was relatively clear because vasospasm occurred shortly after sorafenib administration. Third, the symptoms recurred after re-challenge.

Several hypotheses have been proposed to explain how sorafenib causes coronary vasospasm. One is that it inhibits signaling via VEGF. VEGF inhibition affects vasoreactivity, which causes vasoconstriction by inhibiting vasodilators such as nitric oxide and prostaglandin, which may cause coronary vasospasm. ${ }^{711} \mathrm{~A}$ second hypothesis is that sorafenib inhibits Raf kinase and affects the Raf/MEK/ERK pathway, leading to smooth muscle contraction. Raf kinases participate in the Ras-Raf-MEK-ERK signal transduction cascade. If sorafenib inhibits Raf kinase and decreases Raf/MEK/ERK pathway activity, the Rho/Rho-associated protein kinase pathway, which is involved in sensitization to calcium ions, would become more active, resulting in contraction of endothelial smooth muscle by amplifying calcium ion sensitivity. ${ }^{12,13}$ However, the exact mechanism has not been elucidated, and the incidence of vasospastic coronary artery disease is very low compared to the well-known cardiovascular adverse effects such as hypertension, occlusive coronary artery disease, and thromboembolic events. ${ }^{14,15}$ There is no clinical guidance on whether to re-challenge sorafenib in these patients. Further, there is a lack of consensus regarding the use of other TKI inhibitors as second-line treatment in patients intolerant to sorafenib. At present, patient symptoms should be closely monitored for the development of ischemic heart disease; those with underlying coronary artery disease may suffer lifethreatening consequences if vasospasm occurs. Further research is needed to clarify the mechanism of action of sorafenib and to develop preventive measures.

\section{CONCLUSION}

Coronary vasospasm is a rare cardiovascular adverse effect of sorafenib that can have life-threatening results and may require treatment discontinuation. Careful monitoring for symptom development is recommended. Further research is needed to understand the mechanism by which sorafenib leads to this situation and to develop preventive measures.

\section{Conflicts of Interest}

The authors have no conflicts to disclose.

\section{REFERENCES}

1. Llovet JM, Ricci S, Mazzaferro V, Hilgard P, Gane E, Blanc JF, et al. Sorafenib in advanced hepatocellular carcinoma. N Engl J Med 2008;359:378-390.

2. Chaar M, Kamta J, Ait-Oudhia S. Mechanisms, monitoring, and management of tyrosine kinase inhibitors-associated cardiovascular toxicities. Onco Targets Ther 2018;11:6227-6237.

3. Escudier B, Eisen T, Stadler WM, Szczylik C, Oudard S, Siebels M, et al. Sorafenib in advanced clear-cell renal-cell carcinoma. N Engl J Med 2007;356:125-134.

4. Bruix J, Raoul JL, Sherman M, Mazzaferro V, Bolondi L, Craxi A, et al. Efficacy and safety of sorafenib in patients with advanced hepatocellular carcinoma: subanalyses of a phase III trial. J Hepatol 2012; $57: 821-829$.

5. Touyz RM, Herrmann SMS, Herrmann J. Vascular toxicities with VEGF inhibitor therapies-focus on hypertension and arterial thrombotic events. J Am Soc Hypertens 2018;12:409-425.

6. Orphanos GS, Ioannidis GN, Ardavanis AG. Cardiotoxicity induced by tyrosine kinase inhibitors. Acta Oncol 2009;48:964-970.

7. Lanza GA, Careri G, Crea F. Mechanisms of coronary artery spasm. Circulation 2011;124:1774-1782.

8. Arima Y, Oshima S, Noda K, Fukushima H, Taniguchi I, Nakamura S, et al. Sorafenib-induced acute myocardial infarction due to coronary artery spasm. J Cardiol 2009;54:512-515.

9. Naib T, Steingart RM, Chen CL. Sorafenib-associated multivessel coronary artery vasospasm. Herz 2011;36:348-351.

10. Porto I, Leo A, Miele L, Pompili M, Landolfi R, Crea F. A case of variant angina in a patient under chronic treatment with sorafenib. Nat Rev Clin Oncol 2010;7:476-480.

11. Masumoto A, Mohri M, Shimokawa H, Urakami L, Usui M, Takeshita $A$. Suppression of coronary artery spasm by the Rho-kinase inhibitor fasudil in patients with vasospastic angina. Circulation 2002;105:1545-1547. 
12. Kandabashi T, Shimokawa H, Miyata K, Kunihiro I, Eto Y, Morishige $\mathrm{K}$, et al. Evidence for protein kinase C-mediated activation of Rhokinase in a porcine model of coronary artery spasm. Arterioscler Thromb Vasc Biol 2003;23:2209-2214.

13. Pawlak G, Helfman DM. MEK mediates v-Src-induced disruption of the actin cytoskeleton via inactivation of the Rho-ROCK-LIM kinase pathway. J Biol Chem 2002;277:26927-26933.

14. Choueiri TK, Schutz FA, Je Y, Rosenberg JE, Bellmunt J. Risk of arterial thromboembolic events with sunitinib and sorafenib: a systematic review and meta-analysis of clinical trials. J Clin Oncol 2010;28:2280-2285.

15. Hudes GR, Carducci MA, Choueiri TK, Esper P, Jonasch E, Kumar R, et al. NCCN Task Force report: optimizing treatment of advanced renal cell carcinoma with molecular targeted therapy. J Natl Compr Canc Netw 2011;9 Suppl 1:S1-S29. 